\title{
Biochemical Study of Cerebrospinal Liquid Composition on a Lot of Newborns with Hydrocephaly
}

\author{
ANIKO MARIA MANEA ${ }^{1}$, DANIELA CIOBOATA2 ${ }^{2}$ RAMONA STROESCU ${ }^{3}$, MARIOARA BOIA ${ }^{1 *}$, MARILENA MOTOC ${ }^{4}$ \\ ${ }^{1}$ Victor Babes University of Medicine and Pharmacy, Department of Puericulture and Neonatology, 2 Eftimie Murgu Sq., \\ 300041, Timisoara, Romania \\ ${ }^{2}$ Louis Turcanu Clinical Emergency Hospital for Children, 2 Dr. Iosif Nemoianu Str., 300011, Timisoara, Romania \\ ${ }^{3}$ Victor Babes University of Medicine and Pharmacy, Department of Pediatrics, 2 Eftimie Murgu Sq, 300041, Timisoara, \\ Romania \\ ${ }^{3}$ Victor Babes University of Medicine and Pharmacy, Department of Biochemistry and Pharmacology, 2 Eftimie Murgu Sq, \\ 300041, Timisoara, Romania
}

\begin{abstract}
Hydrocephaly represents the accumulation of cerebrospinal liquid at cerebral level and it associates with the increasing of intracranial pressure with multiple effects at the level of cerebral tissue. The cerebrospinal fluid (CSF) is a fluid with a clear appearance, with a composition that changes depending on gestational age and associated pathology. Newborns, especially premature, are more susceptible to develop hydrocephaly and a significant percentage out of these will develop neurological deficits and complications associated with ventriculo-peritoneal shunt. The study was carried out in the Department of Neonatology and Premature from the Clinical Emergency Hospital for Children Louis urcanu Timisoara, in a period of 3 years (20142016). There were 26 patients included in the study, who presented hydrocephaly diagnosis supported clinically, by ultrasound and CT. There were conducted dosages in dynamics of CSF composition, depending on pathology: malformative, infectious or hemorrhagic.
\end{abstract}

Keywords: prematurity, hydrocephaly, ventricular-peritoneal drainage, cerebrospinal fluid

Hydrocephaly is characterized by abnormal accumulation of cerebrospinal fluid in the ventricular system. This can lead to increased intracranial pressure resulting in progressive growing of cranial diameter, appearance of seizures and retardation of psychomotor development. Hydrocephaly can be caused by congenital or acquired factors. The congenital causes include hydranencephaly, holoprosencephaly, porencephaly, schizencephaly, spina bifida, Arnold-Chiari malformation, Dandy-Walker syndrome. The acquired causes include intracranial hemorrhage, intracranial infections and cerebral tumors.

The cerebrospinal liquid is a fluid with a clear and transparent appearance that fills the cerebral ventricular system, ependimar channel, brain and spinal subarachnoid spaces being secreted mainly by choroid plexus from the level of ventricular system [1]. The cerebrospinal fluid is a metabolically active substance with a composition that changes depending on gestational age and associated pathology. Comparative with plasma, the cerebrospinal fluid has a low concentration of proteins, glucose, potassium and calcium, but high in chlorine and sodium [2, 3] (table1).

Table 1

CEREBROSPINAL FLUID PARAMETERS AT TERM AND PREMATURE NEWBORNS

\begin{tabular}{|c|c|c|}
\hline & Premature Newbom & Term Newbom \\
\hline Nr. of elements/mm3 & 5.1 & 5.5 \\
\hline Proteins (mg/dl) & 72.6 & 68.2 \\
\hline Glucose (mg/dl) & 50.3 & 55 \\
\hline Chlorides (mmol/) & 210 & 200 \\
\hline
\end{tabular}

\section{Experimental part}

It was aimed to follow the association degree between prematurity, hydrocephaly and the causes that determine hydrocephaly, as well as the biochemical composition of the cerebrospinal fluid reported to the associated pathology. The purpose of evaluation of the biochemical composition of the cerebrospinal fluid was to follow the evolution of the patients with ventriculo-peritoneal shunt, ventricular external drainage and the complications of the shunt, especially infections and shunt failure.

The study was carried out prospectively in the Department of Neonatology and Premature from the Clinical Emergency Hospital for Children Louis urcanu Timisoara, in a period of 3 years (2014-2016). There were 26 patients included in the study, who presented hydrocephaly diagnosis supported clinically, by ultrasound and CT. There were conducted dosages in dynamics of cerebrospinal liquid composition, depending on pathology: malformative, infectious or hemorrhagic, the cerebrospinal liquid being harvested in the first week from the placement of ventriculo-peritoneal shunt or external ventricular drainage and then in dynamics, either by lombar puncture or directly from the tap attached to the drainage device.

\section{Results and discussions}

From the 26 cases included in the study 19 patients were premature newborns (gestational age under 37 weeks) and 7 patients were term (gestational age over 37 weeks). From the premature newborns 7 were with low birth weight (LBW-low birth weight), 8 were with very low birth weight (VLBW-very low birth weight) and 4 with extreme low birth weight, under 1000 grams (ELBWextreme low birth weight) (table2).

The predominant cause of hydrocephaly in the studied lot was intraventricular hemorrhage (53.8\%), followed by cerebral malformations (myelomeningocele associated with Arnold Chiari type Il malformation, spina bifida occulta, semilobar holoprosencephaly, porencephaly and encephalomeningocele) with a percentage of $30.8 \%$. In the studied lot 2 cases developed hydrocephaly secondary

*email: marianaboia@yahoo.com; Phone: 0740137597 


\begin{tabular}{|l|l|l|l|l|}
\hline \multicolumn{1}{|c|}{ Gestational age } & \multicolumn{4}{|c|}{ Birth weight $n(\%)$} \\
\hline Term newborns & $7(26.9 \%)$ & TLEW \\
\hline Premature newborns & LBW & LLW & ELBW & Total \\
\cline { 2 - 5 } & $7(26.9 \%)$ & $8(30.8 \%)$ & $4(15.4 \%)$ & $19(73.1 \%)$ \\
\hline
\end{tabular}

Table 2

DISTRIBUTION OF NEWBORNS BY GROUPS OF AGE AND BIRTH WEIGHT

Table 3

CAUSES OF HYDROCEPHALY

\begin{tabular}{|l|l|}
\hline 26 cases of hidrocephaly & $\mathrm{n}(\%)$ \\
\hline Isolated hidrocephaly & $2(7.8)$ \\
\hline Spina bifida occulta & $1(3.8)$ \\
\hline Amold Chiari type III (Encephalomeningocele) & $1(3.8)$ \\
\hline Amold Chiari type II (Myelomeningocele) & $4(15.4)$ \\
\hline Porencephaly + hemorrhage degree 4 & $1(3.8)$ \\
\hline Semilobara holoprosencephaly & $1(3.8)$ \\
\hline Intraventricular hemorrhage & $14(53.8)$ \\
\hline Intracranial infections & $2(7.8)$ \\
\hline Total & $26(100)$ \\
\hline
\end{tabular}

to intracranial infections (7.8\%) and 2 cases were with isolated hydrocephaly (7.8\%), (table 3).

At the lot of premature newborns, especially those with VLBW and ELBW, hydrocephaly was secondary to intraventricular hemorrhage. At LBW hemorrhage the predominant cause of hydrocephaly were cerebral malformations ( 5 cases), only two of them having intraventricular post-hemorrhage hydrocephaly. At the lot of term newborns predominant is the hydrocephaly associated with cerebral malformations.

From the 26 newborn with hydrocephaly, 24 needed surgical intervention with installing, depending the etiology, of an external ventricular drainage or of a ventricularperitoneal shunt. Only 2 cases had a favorable evolution under treatment with medicine with stabilizing hydrocephaly, without the need of neuro-surgical intervention; hydrocephaly being associated with cerebral malformations (holoprosencephaly and spina bifida occulta).

At the 24 patients that had ventricular-peritoneal shunt or external ventricular drainage it was harvested in dynamics cerebrospinal liquid in order to monitor the disease evolution or the complications of shunt and ventricular drainage. At premature with intraventricular post-hemorrhage hydrocephaly there were highlighted, in the cerebrospinal liquid, an increased number of elements (values between $25-45 / \mathrm{mm}^{3}$ ) and modifications of biochemical composition - increased proteins (values between $80-116 \mathrm{mg} / \mathrm{dL}$ ), normal chlorides (192$198.5 \mathrm{mmol} / \mathrm{L}$ ) and normal or mildly decreased glucoses (35.28-63 mg/dL).

Newborns with hydrocephaly secondary to intracranial infection presented a much bigger number of cellular elements comparative with premature $\left(1834-8010 / \mathrm{mm}^{3}\right)$, proteins were highly increased $(87.6-116 \mathrm{mg} / \mathrm{dL})$ and chlorine and glucoses are low (153-176 $\mathrm{mmol} / \mathrm{L}$ respective $5.94-35.28 \mathrm{mg} / \mathrm{dL}$ ). Instead, at term newborn with cerebral malformations as predominant cause of hydrocephaly it was observed only the increase of proteins in cerebrospinal liquid $(78.5-92.3 \mathrm{mg} / \mathrm{dL}$ ), the other biochemical parameters being within normal limits.

From the 24 newborns with shunt or external ventricular drainage, $8(30.8 \%)$ presented infections or shunt malfunction by mechanical obstruction, with the need of a new surgical intervention. From these 7 were premature (hydrocephaly being secondary to intraventricular hemorrhage) and only one was a term newborn with hydrocephaly secondary to a cerebral malformation.

Hydrocephaly remains one of the most devastating forms of neurological injuries. The prevalence of neonatal hydrocephaly, according to the specialty literature, is between 0.48-0.81 at 1000 newborns [4], and a significant percentage out of these will develop neurological deficits, blindness, complications associated to ventricularperitoneal shunt [5].

Premature new borns, and especially those with VLBW or ELBW, present the highest risk to develop neurological post-injury hydrocephaly. In our study, out of the 26 term and premature newborns diagnosed with hydrocephaly, the highest percentage was represented by premature $73.1 \%$. The most frequent cause of hydrocephaly was intraventricular hemorrhage $53.8 \%$, followed by cerebral malformations $30.8 \%$, cerebral infections $7.8 \%$ and other causes $7.8 \%$. In the study carried out on a period of three years (2006-2008), Vassilyadi M, Tataryn Z et al. have reported that $60 \%$ of the hydrocephaly cases had as cause the severe intraventricular hemorrhage (Vassilyadi M, Tataryn Z et al. 2009) [6].

The cerebrospinal liquid at adults contains approximatively 5 elements $/ \mathrm{mm}^{3}$. At newborns the cerebrospinal liquid can present a bigger number of elements up to $15-30 / \mathrm{mm}^{3}$, without being an indicator of cerebral infection [7]. Also, proteins concentration in cerebrospinal liquid is slightly increased at newborns and especially at premature new borns [8]. According to a study performed by Lenfestey et al. the presence of the ventricular-peritoneal shunt or of an external ventricular drainage modifies the biochemical of cerebrospinal liquid with increasing, especially, of the number of elements and proteins (Lenfestey, Smith et al. 2007) [9]. In our study all the newborns presented high quantity of proteins. It was raised the question if high concentration of proteins can be a determinant factor in mechanical obstruction of the shunt. Several studies from the specialty literature showed thathigh concentration of proteins does not affect the valve function, but the increased number of erythrocytes, especially at the hydrocephaly post- intraventricular hemorrhage represents a factor in valve obstruction [ 9 , 10]. This aspect was observed in our study, too, the hydrocephaly being secondary to cerebral hemorrhage at 7 from the newborns with valve complications. Due to immaturity of the immunologic system, to associated medical co-morbidities, fine, thin skin, with high risk of sutures dehiscence, the rate of infections due to ventricular-peritoneal shunt is high. Even unique institutional studies have reported infection rates lower than $1 \%$, in other 27 de studies were reported rates of $5-10 \%$ due to ventricular-peritoneal shunt [11, 12].

In our study the percentage of complications of the shunt, both infectious and due to valve malfunction, was $30.8 \%$. A study conducted on 58 LBW premature with hydrocephaly post-hemorrhage highlighted a percentage of shunt complications of 17.2\% (Fulkerson, 2012) [2], and another study conducted in India on a number of 30 patients showed a percentage of $35.7 \%$ (Kendre et al. 2016) [13].

\section{Conclusions}

The newborns and especially the premature ones are more susceptible to develop hydrocephaly.

The most frequent cause was the peri/intraventricular hydrocephaly.

The perspective for these patients have improved significantly in the last decades, even so despite the medical progress, a small subgroup of newborns will 
continue to develop complications of hydrocephaly and ventricular-peritoneal shunt, being a negative prognostic predictor on a long term.

\section{References}

1.VENKATESH, B., SCOTT, P., ZIEGENFUSS, M. Critical Care and Resuscitation, 2, 2000, p. 42-54.

2. FULKERSON, D. Hydrocephalus. Sadip Pant and Iype Cherian: InTech; 2012, p. 57-68. www.intechopen.com/books/hydrocephalus. 3.MAJUMDAR, A., JANA, A., J ANA A. et al. J Clin Neonatol. 2(4), 2013, p. 166-168.

4.CHUMAS, P., TYAGI, A., LIVINGSTON, J . Arch Dis Child Fetal Neonatal 85, 2001, p. 149-154

5.J AMES, P., MCALLISTER, II. Seminars in Fetal and Neonatal Medicine 17, 2012, p. 285-294

6.VASSILYADI, M., TATARYN, Z., SHAMJ I, M.F., VENTUREYRA, E.C.Pediatr Neurosurg. 45, 2009, p. 247-255.
7.MARTIN-ANCEL, A., GARCIA-ALIX,A., SALAS, S. et al. Arch Dis Child Fetal Neonatal. 91(5), 2006, p. 357-358.

8.SAMIR. SHAH, S., EBBERSON, J., KESTENBAUM, L.A. et al. J Hosp Med. 6(1), 2011; p. 22-27.

9.LENFESTEY, R.W., SMITH, P.B., MOODY, M.A. J Neurosurg. 107(3), 2007, p.209-12.

10.0I, S., Di ROCCO, C. Childs Nerv Syst. 22(7), 2006, p. 662.

11.DRAKE, J.M, KESTLE,J.R.W., MILNER, R. et al. Neurosurgery 43, 1998, p. 294-305.

12.LANGLEY, JM., LeBLANC, JC., DRAKE, JM. et al. Clin Infect Dis 17, 1993, p. 98-103.

13.KENDRE VIDYADEVI, D., TIBREWALA, V.N., KENDRE, VV. International Journal of recent trends in science and technology. 19 (3), 2016, p. 418-420.

Manuscript received: 15.07 .2018 